any known gradation of sea temperature. It not only accounts for the eocene heat when the land in the joth and 8 oth parallels was upheaved by enormous volcanic action; the cooler miocene brought about when this action subsided, and permitted Arctic seas to again find egress; and the cold glacial period when both shores of the Atlantic were frozen by icy currents, as one shore is now; but by shutting off Antarctic currents it might have produced the hottest cretaceous times. Even the latter supposition is rendered likely by the past and present distribution of life, and such conditions doubtless did exist in remote times.

I am, however, speculating beyond the scope of my present paper, for, however the eocene climate was produced, the Arctic floras, I believe, flourished in it. Again I will close my paragraph with an extract from Dawson: ${ }^{1}$ "But overlying this plant-bearing formation we have an oceanic limestone (the Niobrara) .... indicating that the land of the lower cretaceous was replaced by a vast Mediterranean Sea, filled with warm water from the equatorial currents, and not invaded by cold waters from the north. This is succeeded by thick upper cretaceous deposits. . . these show that further subsidence or denudation in the north had opened a way for the Arctic currents, killing out the warm-water animals of the Niobrara group, and filling up the Mediterranean of that period." J. STARKIE GARDNER

\section{AN ENGLISH MTCROSCOPE FOR THE USE OF STUDENTS OF MINERALOGY AND PETROLOGY}

T $T$ may interest those who are studying petrology to know that a new microscope, specially suited for mincralogical and petrological research, has recently been constructed by Mr. T. W. Watson, of Pall Mall.

For several years past students have frequently asked me to recommend some microscope to them which would answer their requirements, and, finding that none of the cheaper instruments manufactured in this country were supplied with concentrically-rotating stages, bearing divided circles, and that even the high-class instruments failed to fulfil all the requirements, it appeared that this want might be supplied at a moderate cost, if one of our instrument-makers could be induced to make a few trials.

An examination of one of the microscopes devised by Prof. Rosenbusch and manufactured by Fuess, of Berlin, showed me that, although that instrument possessed many features of great merit, it also had certain defects which could be best overcome by adopting and modifying a good English model.

The great defects in most of the microscopes built on the continental patterns consist in their fixed vertical position, the smallness of their stages, and, very commonly, in the absence of any means of coarse adjustment, except by a sliding movement of the body or tube, which, if working stiffly, is very inconvenient, while, if sliding easily, is apt to be shifted by a very slight touch.

The microscope of Prof. Rosenbusch, apart from one or two of these defects, is a very admirable instrument, and presents various advantages over all other microscopes hitherto made.

The instrument, now manufactured by Mr. Watson, is in most respects quite equal in performance to Rosenbusch's microscope, so far as the mechanical appliances and adjustments are concerned, and is, I think, in point of convenience, decidedly superior to the latter instrument.

The foot is a brass casting of a pattern somewhat similas to that of Ross and other well-known makers. Upon this a gun-metal limb is supported on trunnions, which constitute the axis upon which the limb turns, so that the instrument can be inclined at any angle, or placed in a horizontal position for drawing. The right trunnion The Princeton Revicw, $1879, \mathrm{p}, 282$ carries a clamp to fix the instrument at any angle. The lower portion of the limb bears the mirror, attached to a jointed arm. The upper part of the limb is bowed, or goose-necked, which renders it convenient as a handle, by which to lift the stand, without entailing any strain upon the working parts of the instrument. Above the curve it is ploughed out to receive the rack of the body or tube (on the pattern known as the "Jackson Model") and the coarse adjustment is effected by a pinion turned by milled heads. The fine adjustment is of the usual kind, and is situated near the lower extremity of the tube. In the stand first made the milled head of the fine adjustment was divided for the measurement of the thickness of sections, but in future it is proposed to effect this object in a different manner by divisions engraved upon the limb and the sliding portion of the coarse adjustment.

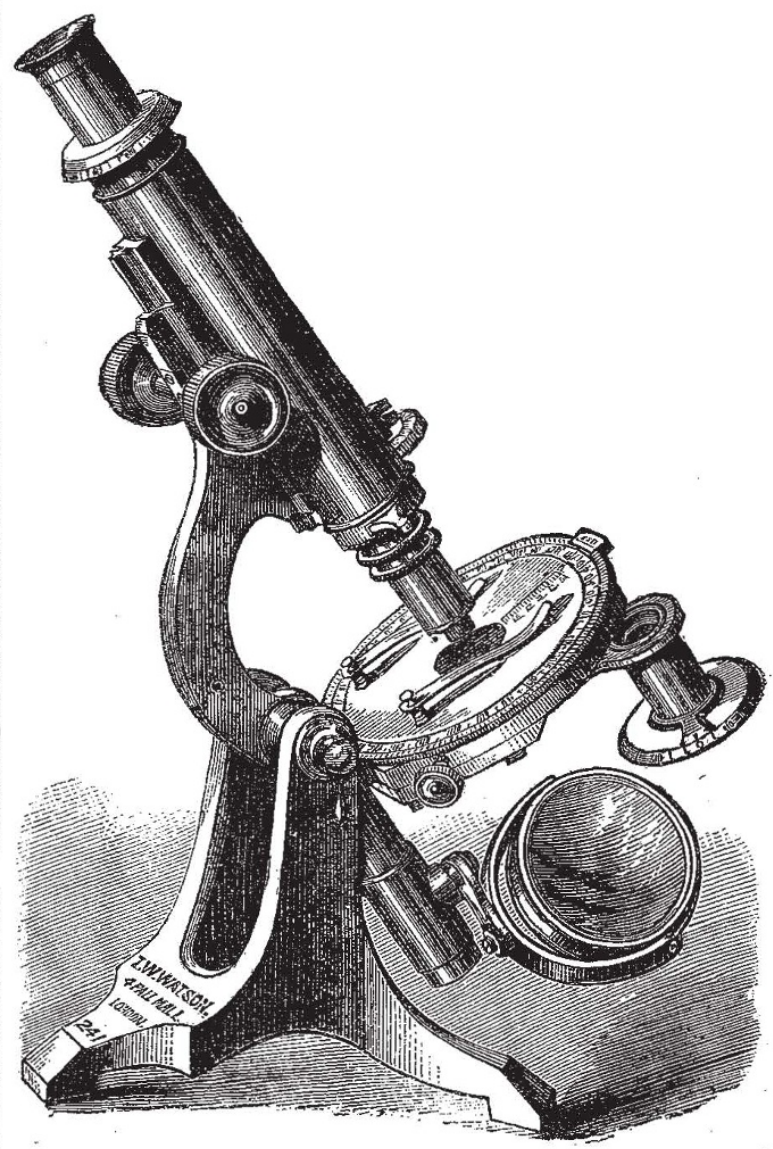

The head of the tube or body carries a bevelled disk which is divided to $10^{\circ}$ spaces. A corresponding disk with an index is attached to the bottom of the analyserfitting, and rests directly upon the fixed divided disk; so that the analyser can be set in any required position, and any amount of revolution imparted to it can also be registered. The eye-piece, when inserted, is kept in a fixed position by a stud, which falls into a small slot. Crossed cobwebs are fixed within the eye-piece for the purpose of centring the instrument. A small plate of calc-spar, cut at right angles to the optical axis, is mounted in a little metal ring, which can be placed between the eye-glass and the analyser for stauroscopic examinations.

At the lower end of the microscope-tube a slot is cut to receive a Klein's quartz plate or a quarter-undulation plate, both of which are set in small brass mounts. When these are not in use the aperture can be closed by means of a revolving collar. 
The thread which receives the objectives is of the gauge commonly used in this country, but an adapter can also be supplied which will carry the objectives of Hartnack and other continental opticians.

The stage is circular and capable of rotation, and it is divided on the margin to $360^{\circ}$. A vernier is attached to the front of the stage, giving readings to one minute. The edge of the stage is milled, and rotation is imparted by hand.

To insure concentric rotation with any powers used, two screws, carrying milled heads, are connected with the back of the stage. By the employment of these adjusting screws and the cobwebs in the eye-piece, a small object may readily be centred, so that it will revolve about a point central to the field afforded by any objective.

The object is held either by sliding clamps or by spring clips, and is moved about by hand. With a little practice this simple method of moving the object will be found to answer every purpose.

The polariser slides into a fitting which is fixed to an arm pivotted on the lower, movable surface of the stage, so that it can readily be displaced when ordinary transmitted illumination is required, and replaced with equal facility.

Two little lenses, affording a strongly-convergent penci of light, are set in metal rings which drop into the top of the fitting which surrounds the polarising prism. When these are employed and the analyser is used, without lenses in the eye-piece (a separate fitting is supplied for this purpose), examinations of the rings and brushes, presented by sections of certain crystals, can be advantageously carried on, and a quarter-undulation plate can also be employed when needful. The lower end of the fitting which carries the polariser is surrounded by a divided disk, turning beneath a fixed index, so that any position of the prism can be recorded and the rotation imparted to it can be measured. Several other useful pieces of apparatus can be added to the stand at a moderate cost.

From the foregoing description it will be seen that this instrument is capable of performing the functions of an ordinary microscope, a polariscope, a stauroscope, and, to some extent, a goniometer. A spectroscope could be fitted to it if needful, as well as an apparatus for heating sections of crystals. For a few pounds separate binocular tubes can be supplied, to replace, in a few seconds, the single, but more generally useful, tube. The objectives of any maker can be used with the instrument.

Having carefully tested one of these microscopes I can speak most favourably of its performance. It is strongly constructed, convenient to handle, and the adjustments work very smoothly. The price of this stand is also remarkably moderate when compared with that of many microscope-stands of far less universal application. It appears to me well qualified to answer the requirements of students of mineralogy and petrology, and it is also applicable to other studies for which microscopes are commonly required.

Mr. Watson has taken especial pains to turn out a sound and serviceable instrument, and, after long experience of microscopes, I can confidently say that I have never seen one better suited for the work for which it is designed. FRANK RUTLEY

\section{STELIAK MAGNITUDES}

\section{A Request to ASTRONOMERS}

THE scales adopted by different observers in their estimates of stellar magnitudes differ considerably from each other, as is well known. As regards the brighter stars, these differences, indeed, are comparatively unimportant; but they become larger and more perplexing when the objects observed are faint. Variations of three or four magnitudes may be expected between the estimates made of the brightness of minute companions seen near a brilliant star. It is needless to point out the inconvenience of this state of affairs, which at times nearly deprives the estimated magnitudes, found in catalogues, of their meaning, and consequently of their value.

In the hope of providing a partial remedy for this defect, a series of photometric observations of stars of various magnitudes, situated near the north pole, has been undertaken at the Harvard College Observatory. The region has been selected as one which may always be conveniently observed in the northern hemisphere, so that the brightness of a star observed in another part of the sky can readily be compared by estimate with any standard polar stars, the relative brightness of which may have been determined by photometric measurements.

The table and chart given below are designed to serve as guides in finding the stars which are, as has been said, in course of phonometric measurement at the Harvard College Observatory. The stars given in the table are arranged approximately in the order of their brightness, the first being a Ursæ Minoris, which is taken in all cases as the standard of comparison, and the next three, $\delta$ Ursæ Minoris, 5I Cephei, and $\lambda$ Ursæ Minoris. The chart is a copy of a sketch showing the approximate relative position of ten faint stars very near the pole, which are denoted by the italic letters $a, b, c, d, e, f, g, h, k, l$. The places

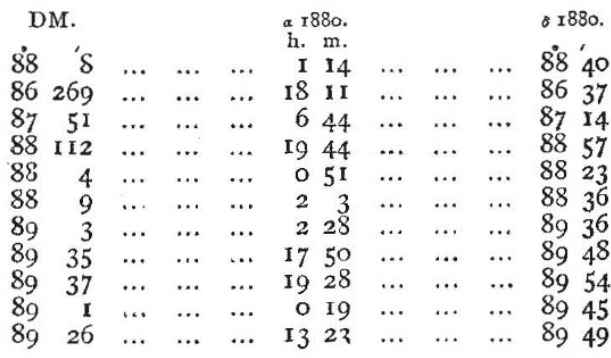

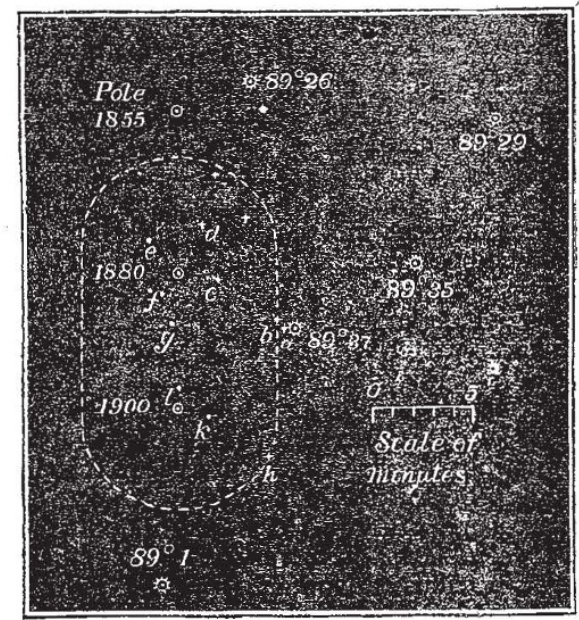

of the pole for 1855,1880 , and 1900 , and of five stars from the Durchmusterung, four of which occur in the table, are also indicated upon the chart, to facilitate the identification of the faint stars. The objects called $c$ and $e$ are nearly in the prolongation of the line through $\mathrm{DM}$. $89^{\circ} 37^{\prime}$ and $b$. Between these last, and more nearly in the same line than it appears to be in the chart, lies the star $a$.

The value and interest of the photometric results to be obtained at the Harvard College Observatory may be greatly increased by the co-operation of astronomers elsewhere. All who are desirous of improving the present 